\title{
Geophysics applied to litho-structural mapping of iron caves, Carajás, Brazil
}

Maria Filipa Perez da Gama*1, Marco Antonio Braga ${ }^{1}$; Marcelo Roberto Barbosa², Rafael Guimarães de Paula ${ }^{2}$ and luri Viana Brandi2; ' UFRJ, ${ }^{2}$ VALE

Copyright 2019, SBGf - Sociedade Brasileira de Geofísica

This paper was prepared for presentation during the $16^{\text {th }}$ International Congress of the Brazilian Geophysical Society held in Rio de Janeiro, Brazil, 19-22 August 2019.

Contents of this paper were reviewed by the Technical Committee of the $16^{\text {th }}$ International Congress of the Brazilian Geophysical Society and do not necessarily represent any position of the SBGf, its officers or members. Electronic reproduction or storage of any part of this paper for commercial purposes without the written consent of the Brazilian Geophysical Society is prohibited.

\section{Abstract}

Natural iron ore caves have been known for centuries but have not attracted much attention because of their small size, scarcity of speleothems, and, in many cases, because of their location in remote areas. With the recent changes in the Brazilian environmental laws and growth of iron ore exploration in the Quadrilátero Ferrífero, Minas Gerais state, and in Carajás, Pará state, Brazil, a substantial number of these caves were discovered and catalogued. The cave environmental legislation requires several technical studies, but mainly on geostructural aspects for the licensing of operations, that are usually long term. Geophysics has shown, in recent studies, the potential to accelerate and improve the lithostructural mapping of caves, especially their roof, to elucidate stability issues. Shallow geophysical methods were used to map and characterize the rock mass in which the caves are hosted. The challenges to the geophysical mapping in these ferruginous karst environments are considerable, because the caves' dimensions are small, and the physical properties of the host rocks are quite variable. In this work, the results of a combined Electrical Resistivity and GPR (Ground Penetrating Radar) geophysical section, executed over a natural cave located in the N4EN iron mine, Carajás Province, northern Brazil, are analyzed and discussed.

\section{Introduction}

The Carajás Mineral Province is known for hosting world class deposits of high-grade iron ore $(60-67 \% \mathrm{Fe})$, manganese, copper, gold and elements of the platinum group. The iron deposits are products of enrichment of the ferriferous formations of the Carajás Formation, of Neoarchean age (DOCEGEO, 1988) composed of banded iron formations represented by jaspilites, and are traditionally classified in three districts (North, South and East ranges), where several discontinuous high-grade ore bodies occur (PEREIRA, 2017). According to these authors, the rocks of the Carajás formation are superimposed to and overlain by mafic rocks. The jaspilites present millimeter to centimeter thick intercalations of light and dark iron oxide and silica bands. Over the iron formations there are large coverings of iron cap, called 'canga', which act as the supporting element of the dissected plateaus, regionally represented by the Carajás range. A large number of caves were recorded in the contact zone between the canga and the iron formation, because the hard carapace of the canga supports or forms the roof of the caves. Piló \& Auler (2009) divided the positioning of caves into three groups: caves positioned on the edges of lagoons on top of plateaus; caves located at the edges of drainage and headwaters; and caves embedded in the sloping edges of the dissected plateaus. The caves are developed inside the canga, within the iron formation or in the contact between the two, as well as in the ferricrete.

Combinations of more than one geophysical method are often used to investigate underground cavities (natural or man-made) and their host rocks, as the results of a geophysical method can help to solve the uncertainties of another one (e.g. DRIAD-LEBEAU et al., 2008; CARDARELLI et al., 2010; PUTIŠKA et al., 2014; FERREIRA et al., 2017). Chalikakis et al. (2011) analyzed the literature on geophysics applied to karst regions and compiled an indicative table of the most appropriate methods for each type of problem, emphasizing that often the combination of more than one method is necessary. Day-Lewis et al. (2017) discussed the applicability of various shallow geophysical methods to environmental problems in fractured rocks, highlighting electrical resistivity as the most appropriate method for identification and monitoring of fractured zones, and GPR (Ground Penetrating Radar) as appropriate for mapping fractured zones, as in large part the electrical properties of the massifs are controlled by the presence of fractures and the connectivity between them.

This study presents the partial results of a combined electrical resistivity/GPR survey over a cave located within the grounds of the N4EN iron mine, in Carajás, northern Brazil. This cave, N4E-0026, was located under the edge of one of the canga plateaus that covered the iron ore in this mine, as illustrated in Figure 1.

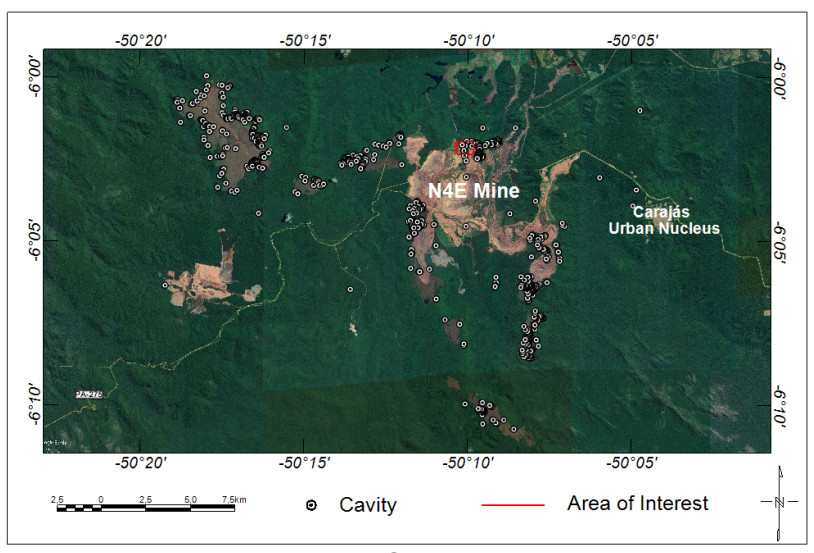

Figure 1 - Location of the Serra Norte caves showing the vast majority of them bordering the 'canga' plateaus 


\section{Study Area}

According to Coelho et al. (2013), the N4E-0026 cave was hosted in jaspilite and detrital canga. The detrital canga occurs on a surface covering the iron ore, with a thickness of up to 20 meters. This type of canga is formed by blocks of hematite cemented by hydrated iron oxides and has a higher Fe content of and lower alumina content than chemical canga, which is the product of the weathering of mafic rocks. The detrital canga could be observed at the end of the cave abruptly set over the altered banded iron formation, and contributed with sediments to the cave floor. The iron formation was highly deformed, with the presence of kink bands, and it presented several subvertical fractures and relief joints, some of which could be mapped from within the cave. Figure 2 shows some altered banded iron formation blocks at cave entrance \#2.

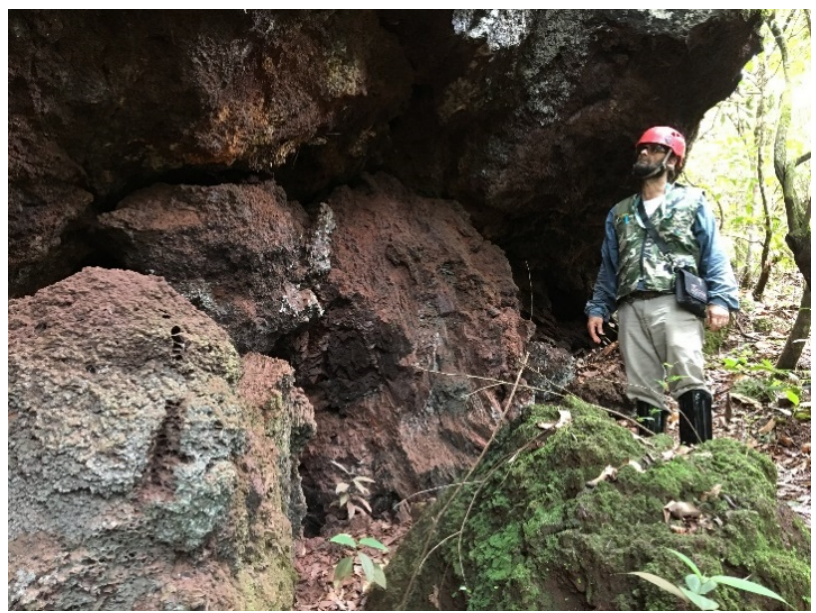

Figure 2 - Cave entrance \#2, displaying large blocks of altered banded iron formation (photo taken in Jan/2018)

A 3-D model of the cave (Figure 3) was created using a Leica Laser Scanner model C10, a compact equipment that can reach even the most inaccessible parts of the cave. The model was converted into a $0.1 \times 0.1 \mathrm{~m}$ voxel which was sliced and superimposed to the geophysical sections. The roof of the cave follows the slope of the plateau, at varying depths between 8 and 12 meters. The maximum level difference within the cave was 15 meters.

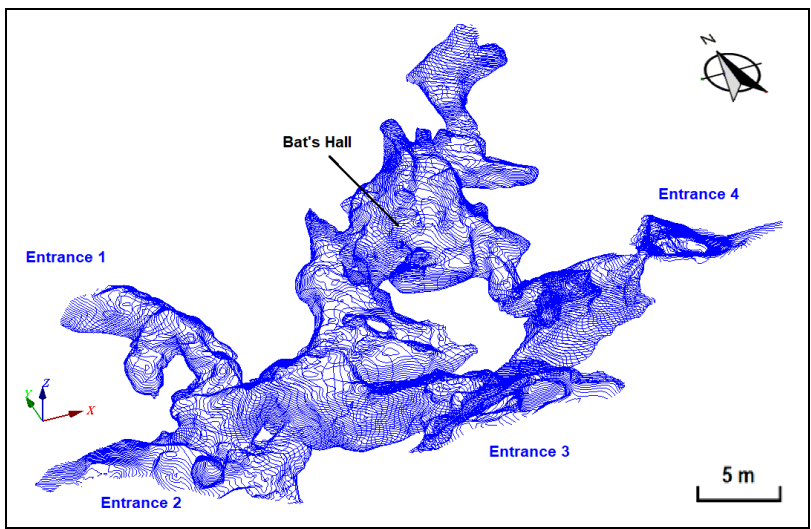

Figure $3-3 D$ model of the cave. The four known entrances to the cave and the largest of the halls are highlighted
The suppression of this cave was permitted by the environmental authorities, and happened in February 2018. Before its suppression it was used for research, including the present study.

\section{Methods}

Two shallow geophysical methods were used: GPR (Ground Penetrating Radar), using antennae frequencies of $80 \mathrm{MHz}$ and $250 \mathrm{MHz}$, and Electrical Resistivity (dipole-dipole array), which are expected, through the joint interpretation, to improve the knowledge of the rock mass above and around the cave, revealing features that can't be observed from the ground or from the inside the cave.

The geophysical sections were acquired on the plateau over the horizontal projection of the cave, by NEOGEO Geotecnologia, contracted by VALE.

Approximately $680 \mathrm{~m}$ of GPR sections were run above the cave N4E-0026, consisting of four $85 \mathrm{~m}$ lines repeated using each equipment and antennae, and approximately $710 \mathrm{~m}$ of electrical resistivity sections, distributed along four $155 \mathrm{~m}$ lines and one $90 \mathrm{~m}$ control line, as shown in Figure 4. The four sections over the cave are oriented $\mathrm{N} 45^{\circ} \mathrm{W}$ and 10 meters apart. Due to the location of the cave, near the plateau edge, it was not possible to obtain continuous measurements along the GPR profiles. One resistivity control section was acquired close to the nearest mine bench, which was later mapped in detail to assist and support the interpretation of the geophysical data. The results of the control section were compared to the lithogeomechanical mapping executed on the mine bench (resistivity control line), as well as the results of L1 (resistivity and GPR, the first line over the cavity area, were compared to the lithogeomechanical mapping of the escarpment face were the largest entrances of the cavity were located.

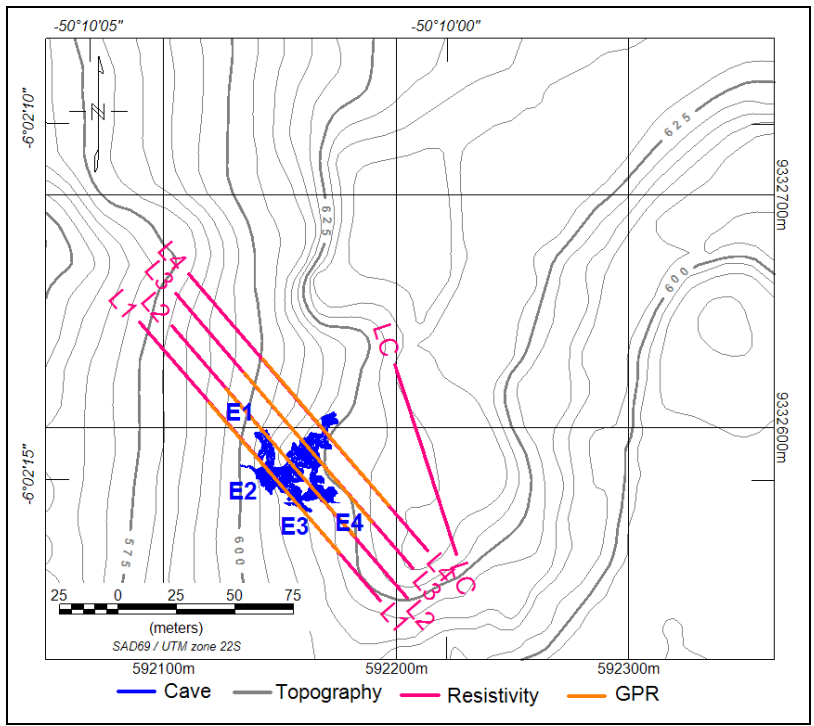

Figure 4 - Location of the geophysical sections near the N4EN mine pit

The electrode array used in the resistivity mapping was dipole-dipole, with $1.4 \mathrm{~m}$ spacing at the control profile and $2.8 \mathrm{~m}$ spacing at the other sections. The equipment was 
an ABEM SAS- 4000 with 64 electrodes and 4 channels. The processing and inversion software used was RES2DINV from Geotomo Software Inc.

The equipment and parameters selected for the GPR acquisition are listed in Table 1. The wave propagation velocity obtained in the initial tests was $0.07 \mathrm{~m} / \mathrm{ns}$. The GPR acquisition was repeated over the same location using different equipment and antennae. The software used for the processing and time to depth inversion was REFLEXW, manufactured by Sandmeier.

Table 1 - GPR equipment and acquisition parameters

\begin{tabular}{|l|l|l|}
\hline Equipment & Pulse Ekko Pro & GSSI \\
\hline Frequency & $250 \mathrm{MHz}$ & $80 \mathrm{MHz}$ \\
\hline Antenna & Shielded & Not shielded \\
\hline Trace interval & $5 \mathrm{~cm}$ & $10 \mathrm{~cm}$ \\
\hline $\begin{array}{l}\text { Number of } \\
\text { samples }\end{array}$ & 500 & 512 \\
\hline Time window & $200 \mathrm{~ns}$ & $500 \mathrm{~ns}$ \\
\hline $\begin{array}{l}\text { Vertical } \\
\text { sampling }\end{array}$ & $0.4 \mathrm{~ns}$ & $1 \mathrm{~ns}$ \\
\hline Stacks & 16 & 16 \\
\hline $\begin{array}{l}\text { Antennae } \\
\text { separation }\end{array}$ & $0.4 \mathrm{~m}$ & $1 \mathrm{~m}$ \\
\hline
\end{tabular}

The field campaign was executed from July to September 2016, during the dry season in Carajás. Several geotechnical instruments, as well as thermohygrometers were installed in the cave and their readings were recorded before the cave was suppressed. Samples of the different lithologies were collected for geotechnical strength tests, and in-situ Schmidt hammer tests were also made before the programmed cave suppression.

\section{Results}

\section{a) Electrical Resistivity}

Three main resistivity domains were observed in the L1 electrical resistivity section, as well as in the control section: LRZ (Low Resistivity Zone), with values of less than $761 \Omega . m$; IRZ (Intermediate Resistivity Zone), with values between 761 and 2718 S.m and HRZ (High Resistivity Zone), corresponding to values higher than $2718 \Omega$.m.

The control resistivity section (LC), located over a mine bench, on the plateau that hosts the cave, was compared to the direct lithogeomechanical mapping of the bench, in order to serve as guidance to the interpretation of the other profiles that crossed the cave. Figure 5 shows the results of this comparison and how the identified resistivity domains correlate to the mapped lithologies.

Figure 6 displays the results of the electrical resistivity section L1 next to entrances 2 and 3 of the cave, as compared to the detailed lithogeomechanical mapping of the escarpment face near the entrances. The points where the escarpment face is closer to the section are also marked in the figure. The main lithology mapped on the escarpment face is Lateritic Iron Formation, as well as on the mine bench.

It is possible to observe the most superficial level, up to about five meters thick, interpreted as the canga crust due to its highest resistivity (HRZ) and also for presenting discontinuous and irregular blocks. The second level, of intermediate resistivity (IRZ), corresponds to the most clayey zone of the lateritic profile, and is shown to be discontinuous near the cave cut where some high resistivity (HRZ) and low resistivity (LRZ) anomalies can be observed. The resistive anomalies around the cave sections can be explained by the fact that the air and cave walls are dry near entrance 2 , the largest entrance (about $12 \mathrm{~m}$ wide by $3 \mathrm{~m}$ high) and entrance $3(11 \times 3 \mathrm{~m})$. The conductive zone (LRZ) observed between the two entrances is interpreted as a more humid zone, where there is percolation of rainwater. The large resistive zone $(>12,000 \Omega \cdot m=H R Z)$ in the lower part of the section corresponds to the iron ore, which in the N4EN mine is composed of friable hematite, known for its high resistivity that can be explained by its high porosity.

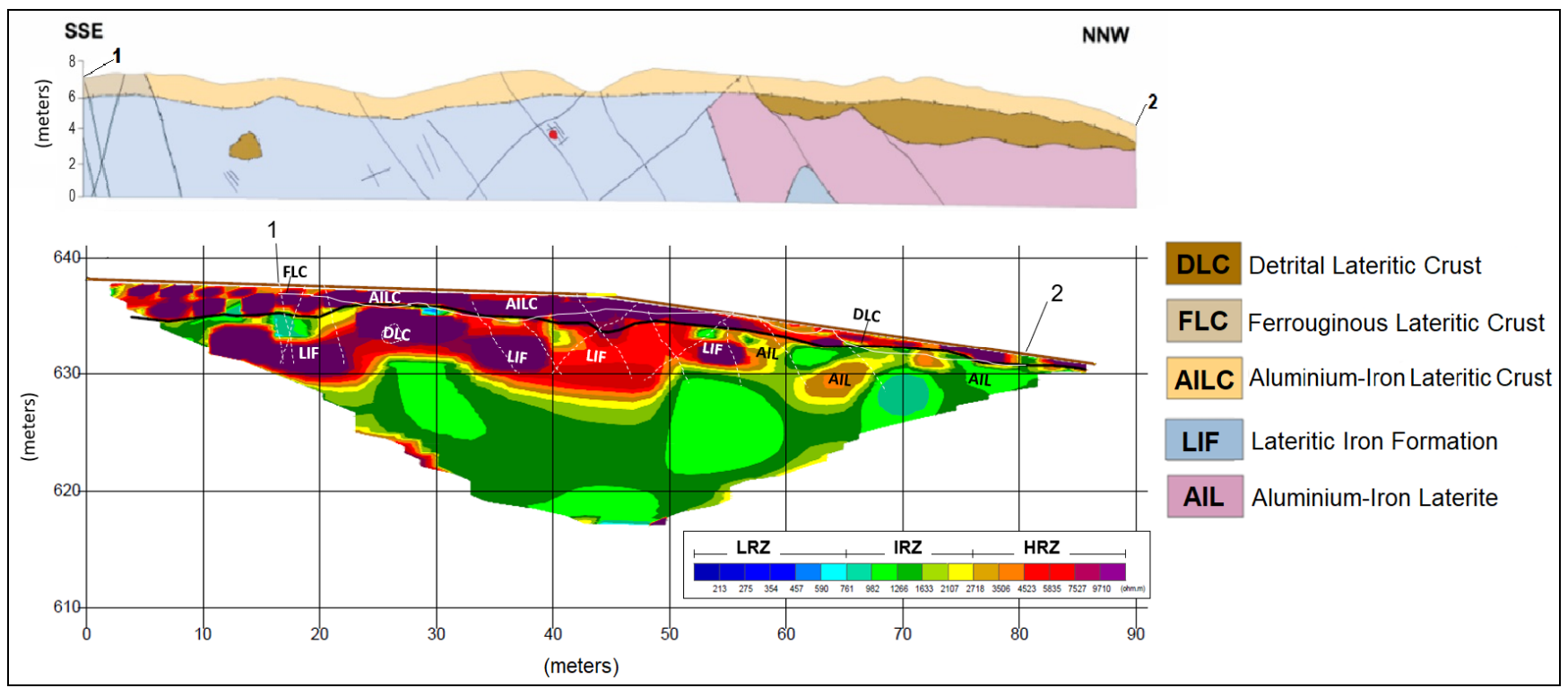

Figure 5 - Lithogeomechanical mapping of the nearby mine bench correlated to the control resistivity section 


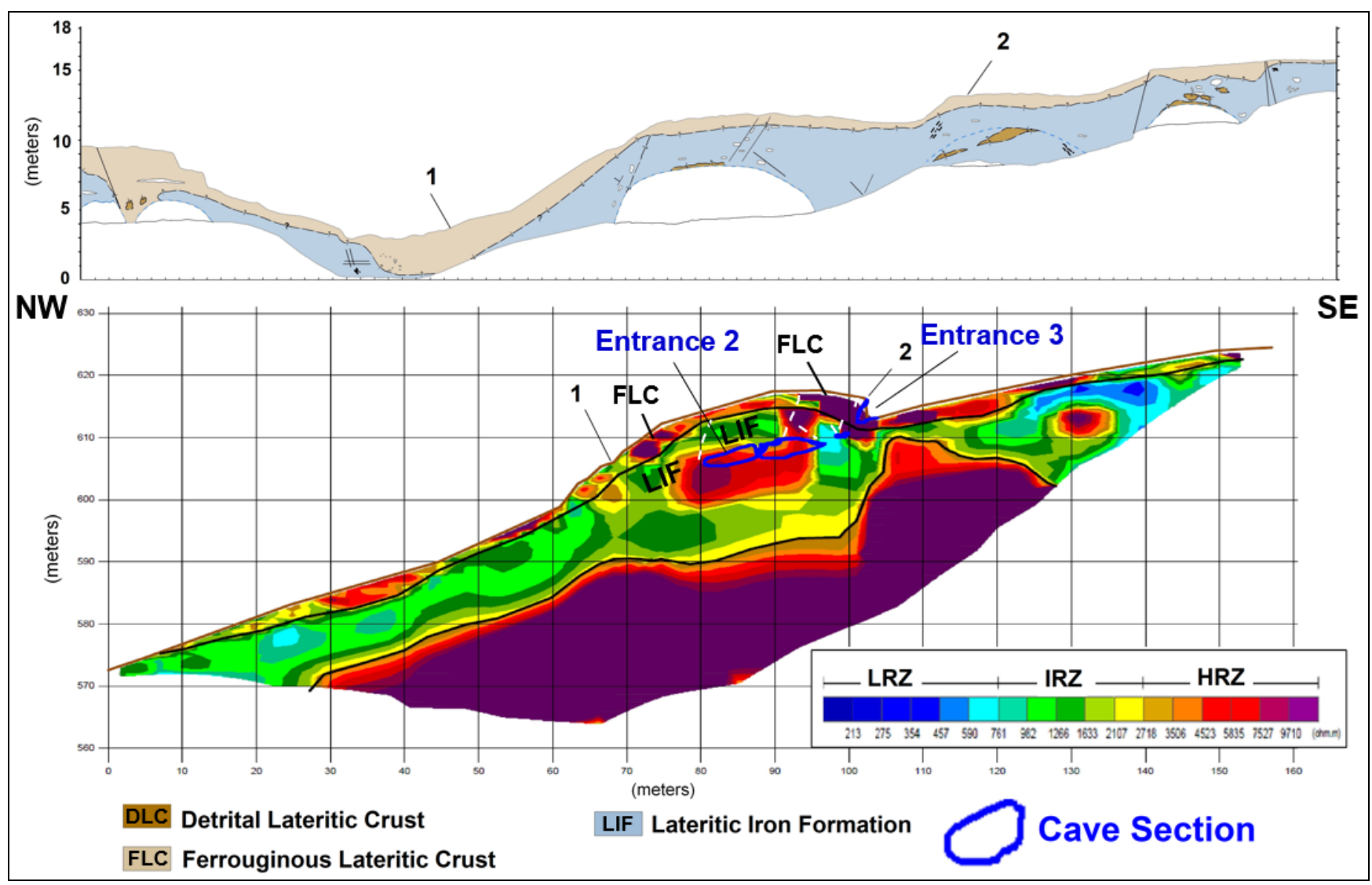

Figure 6 - Lithogeomechanical mapping of the escarpment face around entrances 2 and 3 of the cave, compared to electrical section 1: the three resistivity zones can be clearly distinguished. The largest entrance of the cave was intercepted by this section. The large resistive anomaly at the bottom of the section is interpreted as the iron ore

\section{Ground Penetrating Radar (GPR)}

The GPR sections using the higher frequency antenna $(250 \mathrm{~Hz})$ presented high resolution through the first 6 meters from the ground surface and, as expected, presented a shallow depth of penetration, due to the higher frequency and the more conductive material (JOL, 2009). Figure 7 shows details of the L1 high frequency GPR section, which crosses above and near the cave ceilings.

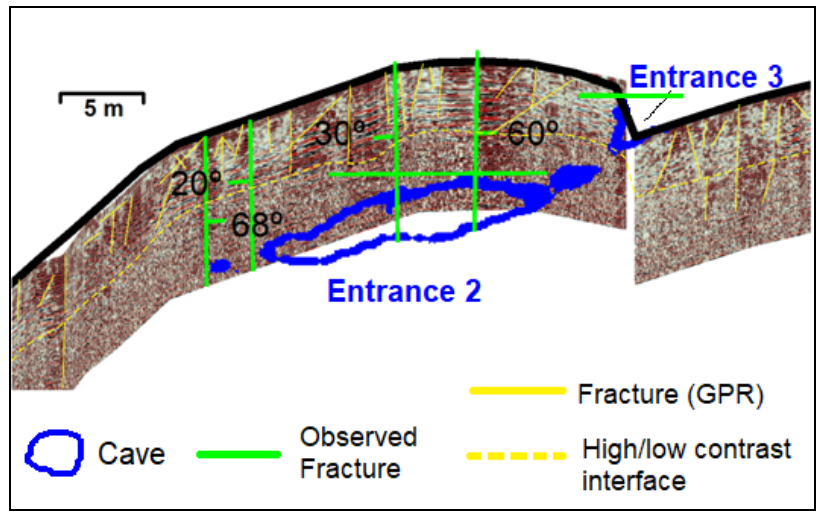

Figure 7 - Detail of the high frequency $(250 \mathrm{MHz}) \mathrm{GPR}$ section 1. The angles between the mapped fractures and the section are annotated. The cave is located in the attenuated part of the profile
The dashed yellow line in the figure shows the depth to which well-defined reflectors can be seen, below which, possibly due to the more conductive clayey material where the caves have developed, the signal is attenuated. Above the cave, the intense fracturing of the rock can be observed, as well as the alternation of contrasted and attenuated reflectors, which can be interpreted as variations in the interface between the canga and the intermediate zone, also observed in the electrical sections. The fractures mapped directly by the geologists from inside the cave are represented in green in the figure, and it can be observed that some of them have direct correspondence with the verticalized features that are observed in the GPR profile.

The GPR section L1 acquired with the low frequency antenna $(80 \mathrm{~Hz})$ shows quite heterogeneous responses in the cave region. The penetration was sufficient to image to a depth greater than the cave's, although the responses were variable (Figure 8). It presented fairly contrasting and sinuous reflections on the cave entrance 2 , indicated by the dashed yellow line, which surrounds the cave, where the section crossed the largest free span. The vertical sequences of reflections, extending from the surface to the base of the section, can be attributed to strong contrasts in the electrical properties of the materials, such as the ferruginous canga and the cavernous texture observed on the mine bench. 


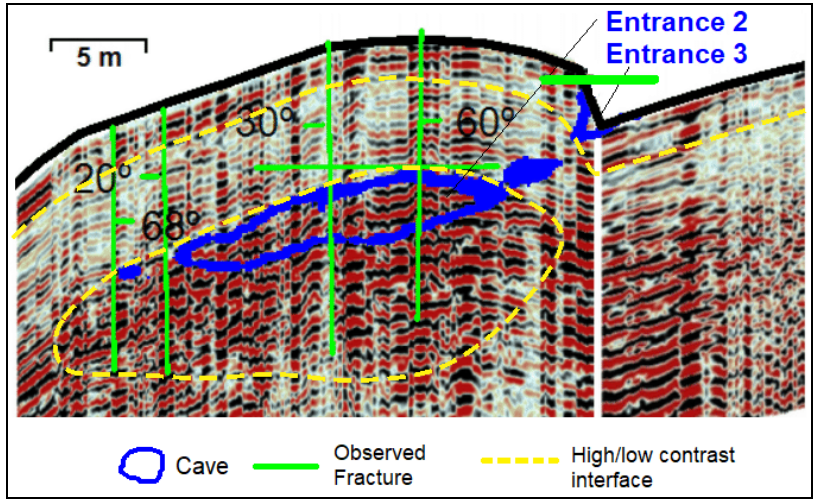

Figure 8 - Detail of the low frequency $(80 \mathrm{MHz}) \mathrm{GPR}$ section L1. High and low contrast regions, as well as discontinuities in the reflectors can be observed

The subvertical fractures observed in the interior of the cave are represented in green in the figure, with the respective angles with which they cut the sections. These fractures seem to have expression in the GPR section, observed as interruptions in the reflectors, although there are many more features of this type in the section than fractures mapped from inside the cave. A difference in thickness and contrast of the reflectors near the surface can be observed in the section, corresponding to the limit of the hardened crust and the more weathered material of the intermediate zone between the canga and the iron ore.

\section{Discussion and Conclusions}

The resistivity sections were effective to map differences in the lithologies, as well possible geotechnical fragility zones, where there is contrast between intermediate and low resistivity, as well as changes in the orientation of the boundaries between the conductive/resistive zones, controlled by the presence of humidity in the fractured zones.

The higher frequency $(250 \mathrm{MHz})$ GPR data were effective in mapping the fracturing or individual blocks in the duricrust cap, but were easily attenuated by the more conductive layer immediately below it, at about $6 \mathrm{~m}$ deep, and weren't able to reach the cave roofs. It can be observed in the GPR sections that the most resistive layer observed in the shallow part of the electrical sections and interpreted as the canga cap has a good correspondence with the most contrasting GPR reflectors. The lower frequency $(80 \mathrm{MHz})$ GPR data had a good penetration depth and mapped well the larger fractures mapped from inside the cave, and revealed others that weren't accessible to direct observation. On the other hand, as expected, the low frequency GPR section presented a lower resolution and many artifacts due to the rugged terrain and reflections from the escarpments, as well as the very heterogeneous and fractured canga cap.

\section{Acknowledgments}

We would like to thank VALE for the data and permission to publish this work.

\section{References}

CARDARELLI, E., CERCATO, M., CERRETO, A., DI FILIPPO, G. Electrical resistivity and seismic refraction tomography to detect buried caves. Geophysical Prospecting, v. 58, n. 4, p. 685-695. 2010.

CHALIKAKIS, K., PLAGNES, V., GUERIN, R., VALOIS, R., BOSCH, F. P. Contribution of geophysical methods to karst-system exploration: an overview. Hydrogeology Journal, 19(6), p. 1169-1180. 2011.

COELHO, A., AULER, A., PILÓ, L. B., FRANCO, F.P. Estudo de Impacto Ambiental de Serra Norte Espeleologia - EIA GLOBAL - Serra Norte (N4/N5). Belo Horizonte, MG, Brazil. 300 pp. 2013.

DAY-LEWIS, F. D., SLATER, L. D., ROBINSON, J., JOHNSON, C. D., TERRY, N., WERKEMA, D. An overview of geophysical technologies appropriate for characterization and monitoring at fractured-rock sites. Journal of Environmental Management, v. 204, p. 709720. 2017.

DOCEGEO, Equipe - Distrito Amazônia. Revisão litoestratigráfica da província mineral de Carajás. In: Província Mineral de Carajás-Litoestratigrafia e principais depósitos minerais. In: Anexo do 35ㅇ Congresso Brasileiro de Geologia. Belém. p. 11-56. 1988.

DRIAD-LEBEAU, L., PIWAKOWSKI, B., STYLES, P., BOURGEOIS, B., CONTRUCCI, I. Geophysical detection of underground caves. In: Symposium Post-Mining. Vandoeuvre-lès-Nancy. 17 p. 2008.

FERREIRA, A.A., LOPES, P., SALOMÃO, M.S., MANE, M.A., GERALDES, M.C., CINTRA, H. Caracterização de cavidades naturais no Parque Estadual do Ibitipoca (Minas Gerais) por meio da pesquisa geológico-geofísica. Espeleo-Tema, v. 28, n. 1, p. 49-59. 2017

JOL, H. M. (Ed.) Ground penetrating radar theory and applications. Elsevier Science, 544 pp. 2009.

PEREIRA, H. S. Integração de dados geológicos, geoquímicos, espectrorradiométricos e de propriedades físicas de rocha: o estudo de caso do Corpo N5S, Província Mineral de Carajás. MSc Thesis. UNB. Brasília, DF, Brazil. 150 pp. 2017.

PILÓ, L. B. \& AULER, A. Geoespeleologia das cavernas em rochas ferríferas da região de Carajás, PA. In: Congresso Brasileiro de Espeleologia. v. 30. p. 181-186. 2009.

PUTIŠKA, R., KUSNIRAK, D., DOSTAL, I., LACNY, A., MOJZES, A., HOK, J., PASTEKA, R., KRAJNAK, M., BOSANSKY, M. Integrated geophysical and geological investigations of karst structures in Komberek, Slovakia. Journal of Cave \& Karst Studies, v. 76, n. 3. p. 155-163. 2014. 